\title{
Learning about death: a project report from the Edinburgh University Medical School
}

Ian E Thompson EMG Research Project in Medical Ethics and Education, C P Lowther Royal Victơ⿱ia Hospital, Edinburgh, Derek Doyle St Columba's Hospice, Edinburgh, Jeremy Bird and Jane Turnbfll Edinburgh University Medical School

\section{Authors' abstract}

$A$ report of a problem-based learning project on the ethics of terminal care, offered as one of the options available to first year $M B C h B$ students in Edinburgh University Medical School. The project formed part of the 'clinical correlation course' in the new curriculum. Six students took part under the supervision of two clinical tutors and a moral philosopher. The course was case-based and practical with students being given the opportunity over a period of eight weeks to meet patients, relatives and hospital staff at a local geriatrics hospital and terminal care home. The main issue studied was the degree of choice available to patients electing to be treated at home, in hospital or in a hospice. Other issues included: pre-death, disposal of the dead, certification of death, communication with relatives and follow-up bereavement services.

\section{Introduction}

'The subject (care of the dying and the bereaved) is being exhaustively researched, there is a growing literature, and there is no longer any excuse, on practical or on academic grounds, for excluding its consideration from the training of doctors and nurses. The question is how best this can be achieved.' Una MacLean. Learning about death (fournal of medical ethics, June 1979, Volume 5 number 2, pp. 68-70).

As previously reported (I) the Edinburgh Medical Group (EMG) Research Project in Medical Ethics and Education was responsible for introducing a form of case-based and multi-disciplinary teaching of medical ethics in a number of clinical and other departments in the Edinburgh University Medical School. A further part of the EMG Research Project consisted in a 3 year Study Project on 'Professional attitudes and values in the care of the dying and the bereaved'(2). Partly as a result of this Study Project and following the successful experiments in integrated teaching of medical ethics, the EMG Research Staff were approached by the Chairman of the Undergraduate Medical Education Committee and asked to supervise two problem-based learning projects on terminal care and abortion for medical students doing the clinical correlation component in Phase I of the new $\mathrm{MB}$ ChB curriculum in Edinburgh. Projects on these topics were supervised last year (1979/80) and are being supervised this year (1980/8I). However, this paper represents comment from medical students, clinical supervisors and ethics tutor specifically involved in the problembased learning project on the ethics of terminal cagre during the $1979 / 80$ academic session.

The overall objectives of the clinical correlation component of Phase I of the MB ChB courseinin Edinburgh are the following:

a) To make students appreciate the relevance and importance of an understanding of the basic medical sciences to performance of good clinical work.

b) To give students the opportunity, early in their training, to meet, talk to, and adapt to patients to those with whom they will work, in order teat they may begin to develop their capacities fo communicate and to form effective work relationships with people of different ages, badkgrounds and expectations.

c) To stimulate the students with some clinfol medicine.

d) To give students the opportunity to investigat $\overrightarrow{\text { in }}$ some depth, and as members of a team, a topic in which they are personally interested.

The 163 students in the class were offered a choice of 22 different problem-based learning projects. These ranged over a wide number of topics including studies of: hypothermia, problems of population growth, changes in blood volume, maternal attitudes to post-natal care etc. Thus the projects on ethieal topics were only two of those on offer. Students were allocated to the different projects according to their indicated preferences. Groups ranged in size from 5-12, and 6 students were assigned to the projectron the ethics of terminal care. The projects spanned two terms, and one day per week for 12 weeks assigned to project work. However, some enthusiastic students spent more time on their projects timn was formally allocated. Besides completing the practical assignments which formed part of ee्षch problem-based learning project, the students were expected to present a live illustrated report of their project to the whole class and to submit a writen report to the faculty as well. Thus the projects were designed to develop and test a wide variety of skifs.

The problem-based learning project on the ethics of terminal care was a complex one involving a major project undertaken by the whole group and relevefnt mini-projects undertaken by individual members of the group or pairs of individuals. The cental 
problem investigated by the group was the extent and limits of patient choice in the matter of where to die - in hospital, in a hospice or at home. This topic was chosen because it was thought that it might prove a useful way of opening up questions about the scope of the rights of the dying and the responsibilities of those caring for them. In particular the students were encouraged to consider the way the following rights are interpreted or applied in practice: the right to know/not to know, the right to privacy/public assistance, the right to treatment/ to refuse treatment. They were also encouraged to consider how the status of the patient changes or is affected depending on whether he is in his own home, in hospital or in a hospice. Thus the question of what the right to a good death means in practice for the patient, the family, and the hospital staff was to be considered not in the abstract, but in relation to the examination of different patients in their different circumstances.

At least ten cases were discussed in considerable detail with the students and these were chosen to illustrate the wide range and variety of problems encountered in the management of dying patients. These included death of a young person following a road traffic accident, death of a middle-aged man by self-poisoning, death of a young mother from breast cancer, and death of an elderly stroke victim. In the Royal Victoria (Geriatrics) Hospital and St Columba's Hospice the students encountered two different patient populations, differing in average age and pathology - in the former the average age about 80 and suffering from the multiple pathology associated with ageing, in the latter (average age about 60 ) where 95 per cent were suffering from cancer. In several instances the cases discussed related to patients whom the students met in one or other of the two institutions. Quite fortuitously they became closely involved in the death of one patient an elderly patient whom they met and spoke to one week and were taken to see in the mortuary two weeks later.

The mini-projects which were undertaken by the group as part of the larger project included study of: the relevant background literature and specific cases, the process of decision-making by the hospital/ hospice team, barriers to communication between doctor and patient, what prevents long-stay patients going home, a day in the life of a long-stay patient, the process of certifying a death and informing relatives, disposal of the dead, supportive care of bereaved relatives, stresses on hospital/hospice staff. In the course of doing these mini-projects the students met and talked to a number of patients, hospital staff and bereaved relatives. They witnessed the medical examination of a patient who had died, and the process of certification of death. However, they were unable to visit dying patients at home, as this was considered too intrusive and therefore inappropriate; but they were able to discuss the problems of home-management of the dying with relatives and home-care staff.

In the following two sections the clinical supervisors, Dr Lowther and Dr Doyle, give their observations on the four week periods during which the students were attached to the Royal Victoria Hospital and St Columba's Hospice, respectively.

IAN E THOMPSON

Research Fellow

\section{Terminal care in a geriatrics hospital}

The first year students were met on four occasions at the Royal Victoria Hospital when they attended between the hours of 10.30 am and $r .00 \mathrm{pm}$. The time spent with them was divided roughly into three parts on these occasions. The first part consisted of a brief discussion on some particular aspect of the care of the dying. Thereafter the second session consisted of the student being introduced in the wards to various clinical problems, but also to patients, whom they were encouraged to sit down and talk with for periods of 10-20 minutes. Thereafter the particular difficulties experienced by these patients were discussed with students. A further period of the session was taken up with the introduction of various project proposals and after they had selected the one which they wished to study they were introduced to those members of the hospital staff who would most readily be able to discuss with them the particular problem which they had selected. Thus for two sessions of their two and a half hours stint they were in the ward and in contact with a variety of hospital staff, varying from the head porter through members of the nursing, ancillary and medical staff.

The topics introduced and discussed with them in the preliminary sessions each morning included the following:
a) The signs of death. What and when is dying ?
b) Death in old people. So-called 'pre-death' phase in severe disability.
c) The change in emphasis in management from therapeutic optimism to settling for comfort and the changing basis of the 'contract' with the patient.
d) Dilemmas relating to unconsultable patients and the rights of relatives at this juncture.
e) Problems such as surgical procedures and artificial feeding during the dying phase.

When the students talked with patients they did not discuss the above topics with them. This part of their course was directed towards introducing them to patients in wards, in some cases, dying patients, and endeavouring to get them to make human contact with patients for the first time. None of them appear to have had any difficulty in making appropriate contact, and the topics of conversation included the weather, the food in the hospital, but also complaints and symptoms and the feelings of patients being in 
hospital, particularly a Geriatrics Hospital. At this time they were given three case histories of patients now dead who had provided us with serious dilemmas in management. Some of these dilemmas were medical and some were ethical but most had elements of both. These cases were useful in so far as, having followed the patient to the end, we were able to discuss how successful our management had or had not been.

The final session each morning involved the selection of topics from a group offered to them which we could back up with staff and, if necessary, patient contact in hospital. These projects centred round nine questions which were as follows:

I) Does privacy for patients exist in hospital wards ? Do they wish it ?

2) How are the dead disposed of ?

3) What is the process of certification of death?

4) How often are patients in long-stay wards visited by friends and relatives? Do patients feel they are visited enough ? If not, why not?

5) Who decides the direction of management, the physical care of patients, the allocation of single rooms, and the conduct of drug therapy in terminal patients ? How much real consensus and consultation is involved?

6) Why can't patients in long-stay wards go home ?

7) To what extent are decisions on terminal care technical and to what extent are they value judgments?

8) What barriers in communication exist between patient and doctor?

9) What is the character of the patient's day in long-stay wards?

Each of these questions was expanded by a number of additional questions and statements indicating in what direction the student might like to advance the project. The students, acting alone or in pairs, made a selection of one topic from the above list. They then decided how they were going to work towards the answers to these questions, the topics were discussed with them and they were placed in contact with other members of the staff who would be able to help them to advance the project.

Thus, in the time available they had sessions of quite close didactic teaching, periods of direct contact with patients, and also periods when the students were working by themselves on their own projects, seeing patients, members of staff, and formulating their own conclusions. Some students were able to see patients who were on the point of death without, of course, causing any disturbance to such patients. Others were enabled to see a patient who had newly died, and with reference to whom the question of certification and informing relatives was imminent.

In general, we enjoyed this contact with students, who were all extremely bright and persistently questioning. They clearly could not be expected to have developed any kind of clinical judgment $\stackrel{2}{\text { in }}_{\text {na }}$ these matters, and had to accept the judgments 5 of members of the staff, but they saw how conclusions on the care of the dying were reached and how clinical care in this area involved both clinical judgments and value-judgments, and dilemmasoof both a medical and ethical nature.

C P LOWTAR
Consultant Physician

\section{Terminal care in a hospice}

At St Columba's Hospice, a specialist terminal carre unit, the students had the opportunity to hæ्चe contact with patients of pre-retirement age aind younger, dying of cancer. At the same time they were able to meet informally some of their relatiges and members of the hospice staff. They were given opportunity to study some of the details of symptom relief for the physical, emotional, social and spiritural distress of patients, as well as attempts to support and encourage the relatives, both before and after the patient's death.

In addition it was planned to demonstrate the difficulties met in providing a specialist service for the dying. These included: decision-making sin relation to care programmes, the involvementof both patients and relatives in such decisions; talking to patients facing death; the creating maintaining of as relaxed, homely and safe $\mathrm{Fan}$ environment as possible for patients whilst deteloping the requisite clinical professionalism for gogd terminal care; keeping open vital lines of communication and cross fertilisation with general medical units and their staff; and, finally, looking at somøof the problems of sustaining staff morale in sucis a setting.

Though not setting out specifically to study 'lồss' it was realised that this would be a recurrent theme in all contacts with patients and staff. It soon becone apparent that the students were reminded of toss within their own experience and lives, through death or social change, and forced to study their ofyn reactions to it. At the same time, they were encouraged to develop a heightened sensitivity to the suffering and stresses confronting the dying, and equally important, to the subleties in communication in relations between sufferers and those supporiting them.

As was to be expected the students quickly assimilated statistics and simple clinical fatts though none had clinical experience beyond thafof a temporary hospital porter! Encouragingly, they displayed a mature and deeply thoughtful attitudêtto a highly articulate patient who spoke of his suffering, his deepest feelings and some of his disappointments in his doctor's behaviour, only two days before his death. Equally, they appeared to learn much from a profoundly thought provoking talk with a tan 
whose wife was enduring a lingering death in the prime of life.

The students tended to make unfavourable comparisons between terminal care in general hospitals and a specialist unit such as a hospice. Through lack of experience they failed to make allowances for the different care-objectives and priorities, and staff/patient ratios in the different kinds of institutions. All who worked with these students, however, look back on their encounter with them certain that their vision was widened, while their sensitivity to both the needs and the rights of the dying patient was stimulated by this experience, novel and occasionally traumatic as it was.

DEREK DOYLE

Medical Director

\section{Student comment on the project}

In the course of this problem-based learning project we learned that the modern attitude toward death, which has been described as a 'conspiracy of silence', is partly due to better medical care, increased life expectancy and hence greater unfamiliarity with death and dying. 'Death is not around like it used to be'. The result is that both family and society seek to protect the patient from the ordeal of dying and to protect themselves from the pain of having to contemplate death. Both factors drive towards the hospitalisation of the dying.

The increasing medicalisation of death is the natural consequence of this process. This means that the rights of the dying have to be examined in practice in an institutional context and in terms of the relationship between the patient and the hospital or hospice team - a relationship governed by professional ethics and the institutional values of hospitals or other terminal care institutions. The reality of death in present day society is that of the relative helplessness of the individual in a large institution-despite the advent of hospices and those who choose or happen to die at home.

As first year students, we were placed in the rather novel position of being able to study terminal care at the very beginning of our course. We were given the opportunity to consider critically this highly specialised, yet universally relevant part of medicine-namely how doctors sometimes have to change direction from cure to care-before being exposed to doctrinaire clinical medicine. The aim of the project was to illustrate, first and foremost, the moral dilemmas of terminal care, but it was also hoped that the sensitivity and insight gained by the group would transcend our formal medical education and decisively affect our professional attitudes at a formative stage.

The project was case-based, and sought to start from the ordinary judgments of people with experience of terminal care. It sought practical rather than theoretical objectives and moral agreement based on rational consensus rather than upon $a$ priori principles.

How did the project affect us? The theme of bereavement touched us all closely. Most members of the group had a personal reason for choosing this project and we felt it would give us opportunity to examine our own reactions, fears and guilt, which we carefully concealed at the outset.

We soon discovered much common apprehension about death, and sensitivity to issues of personal loss amongst ourselves. This in itself gives some indication of the emotive and involving nature of the project-which at all times pervaded its more formal teaching aspects. The project was at once disturbing and sobering, tragic yet uplifting, and we were able as a group to explore together many profound and thought-provoking situations.

We were particularly struck by the change in emphasis between the general hospital and the carebased hospice. We were continuously aware of the organisational problems which beset medical and allied staff in the provision of a well-integrated informative programme running concurrently with the education of general medical and home-care staff. Many points taught in our formal sociology course were much more powerfully and unforgettably illustrated by our contact with the people involved.

The project aroused a great deal of interest and discussion among other students in our year and we found ourselves discussing it with friends and family, medical and non-medical, older and younger associates. This brought home to us the desire of most people to probe the death taboo, given the opportunity. It also underlined for us the need for health-professionals to have insight into and sensitivity to the subtle problems of caring for the dying and the bereaved.

A point which cropped up continuously was the way the doctor/patient contract changes when the doctor can no longer offer curative but only palliative treatment. The duty of the doctor to ensure a pain-free, comfortable and dignified existence for the patient, to be concerned with his quality of life rather than quantity of life is the vital thing. Neither the excessive use of heavy sedation with patients who wish to remain alert, nor the under-use of opiates in intractable pain for fear of habituation, are good examples of terminal 'care'.

It is only by examining critically ourselves the justification for pursuing present medical practice or social taboos in treating the dying that we can begin to regard the patient as a person with rights and not just a failure of medical technology. Too often it is assumed that the medical student once qualified will automatically possess the ability to cope with these highly stressful issues. In one of our 
early sessions we were cast in the role of a hospital doctor obliged to impart the news of a death to the parents of an accident victim. "What would you actually say ?' It is always a traumatic experience, we were told, because no medical course formally prepares you to face the problem or its emotional sequelae. The very considerable interest created by this project amongst our classmates and acquainances and particularly among those who attended our formal presentation was most gratifying. The gain for all of us who contributed to this unique project has been the opportunity in company with many others, to probe the death taboo, and to think critically of the ethical consequences and justification of professional judgments in terminal care. Our thanks to all concerned for making this experience possible. It will surely enrich us and deepen our insight as we are carried forward on the conveyor belt of medical education.

JEREMY BIRD AND

JANE TURNBULL

Medical Students

\section{Co-ordinator's Assessment}

This project aroused a great deal of interest and enthusiasm among staff and students alike. The students' enthusiasm was shown by the liveliness of their class presentation, the fact that they prepared a 30-page detailed report, and that they were keen to contribute to this account of their project. The staff assessment of the project was that it was one of the most successful and in a class survey it was rated more highly than any other. There was unanimơ agreement that it should be repeated.

Criticism of the project can be offered from to points of view: first, that in our enthusiasm overloaded the project, imposing on the students greater demands than were perhaps fair in a limited part of their clinical correlation course; secom, that we supplied more didactic input than was eit necessary or desirable in a problem-based learnigg project in which the students were expected to find out things for themselves. Some students in other groups complained that these projects took up tô much time and detracted from their other studiess. Our group did not complain, but might well hape done for they put in much more work than was required of them. With their help the course 俺s been simplified and streamlined this year.

\section{References}

(I) Boyd K M, Currie C, Thompson I E, Tierney A $\vec{J}$. Teaching medical ethics: University of Edinburgh. fournal of medical ethics 1978; 4: 14I-145.

(2) Thompson I E Dilemmas of dying: a study in 薄e ethics of terminal care. Edinburgh, Edinbugh University Press, 1979.

\section{Editor's note}

Any readers wishing to know more or take up anyö the points raised in the above paper should cont Dr Ian E Thompson, 28 Links Street, Musselburgh EH2I 6JL, Scotland or: Edinburgh Medical Gromp Research Project in Medical Ethics and Education, 24 Buccleuch Place, Edinburgh EH8 9LN, Scotland. 